\title{
Decreased Inositol 1,4,5-Trisphosphate Content in Pathogen-Challenged Soybean Cells
}

\author{
Toshiro Shigaki and Madan K. Bhattacharyya \\ Plant Biology Division, The Samuel Roberts Noble Foundation, P.O. Box 2180, Ardmore, Oklahoma 73402 , \\ U.S.A. \\ Accepted 12 January 2000.
}

\begin{abstract}
Phosphoinositide-specific phospholipase C (PI-PLC) has been shown to be transiently activated when plant cells were treated with elicitors. We thus investigated the activity of PI-PLC when soybean cells were infected with the bacterial pathogen Pseudomonas syringae pv. glycinea, by measuring cellular cytosolic inositol 1,4,5-trisphosphate $\left(\mathrm{IP}_{3}\right)$ levels. We observed that $\mathrm{IP}_{3}$ content decreased in both compatible and incompatible interactions. In vitro phosphatase activities were similar in both water control and infected cells with slightly lower $\mathrm{IP}_{3}$ degradation observed for infected cells, indicating that the reduced $\mathrm{IP}_{3}$ content in infected cells most likely results from reduced PI-PLC activity. We hypothesize that reduced $\mathrm{IP}_{3}$ content following infection may lead to suppression of various housekeeping activities of the cells, thus diverting the cellular resources either to the synthesis of defense-related compounds against pathogens, and/or to the growth of pathogens.
\end{abstract}

Additional keywords: oxidative burst, signal transduction.

Phosphoinositide-specific phospholipase C (PI-PLC) hydrolyzes phosphatidylinositol 4,5-bisphosphate $\left(\mathrm{PIP}_{2}\right)$ on the plasma membrane generating cytosolic inositol 1,4,5trisphosphate $\left(\mathrm{IP}_{3}\right)$ and plasma membrane-associated diacylglycerol (DAG), both of which serve as second messengers in many animal signal transduction pathways (Dennis 1983; Majerus 1992; Singer et al. 1997). These two molecules are known to modulate intracellular events through the regulation of intracellular free $\mathrm{Ca}^{2+}$ and protein kinase $\mathrm{C}$ isozymes (Singer et al. 1997). Many components of the animal phosphoinositide signaling pathway are also found in plants (Coté and Crain 1993; Munnik et al. 1998). Recently, several plant PI-PLCs have been cloned from soybean, Arabidopsis, and potato (Shi et al. 1995; Hirayama et al. 1995; Kopka et al. 1998; Hartweck et al. 1997).

Physiological roles of PI-PLCs in plants have been proposed in a number of systems. In Catharanthus roseus cells,

Corresponding author: M. K. Bhattacharyya

E-mail: mkbattach@noble.org

Present address of Toshiro Shigaki: Plant Physiology Laboratories, Children's Nutrition Research Center, Baylor College of Medicine, 1100 Bates St., Houston, TX 77030, U.S.A. auxin application relieved cell cycle arrest in G1, which was preceded by transient changes in $\mathrm{IP}_{3}$ and inositol 4,5bisphosphate $\left(\mathrm{IP}_{2}\right)$ (Ettlinger and Lehle 1988). Abscisic acid treatment of guard cell protoplasts of Vicia faba induced a $90 \%$ increase in levels of $\mathrm{IP}_{3}$ within $10 \mathrm{~s}$ of administration, suggesting a possible role of PI-PLC in guard cell shrinking and stomatal closure (Lee et al. 1996). In Samanea saman (a legume), 15 to $30 \mathrm{~s}$ of white light pulse caused an increase in $\mathrm{IP}_{3}, \mathrm{IP}_{2}$, and DAG in the pulvinus (motor organ) (Morse et al. 1987, 1989). Recently, it was proposed that a sustained increase in $\mathrm{IP}_{3}$ is responsible for pulvinus cell elongation in maize (Perera et al. 1999). $\mathrm{IP}_{3}$ was also involved in $\mathrm{Ca}^{2+}$ mediated pollen tube inhibition in Papaver rhoeas (FranklinTong et al. 1996).

Plants respond to pathogen attack by activating various defense mechanisms, including hypersensitive cell death. Based on elicitor studies, involvement of elevated levels of $\mathrm{IP}_{3}$ was suggested to play a role in triggering these responses. For example, oxidative burst, a cause of hypersensitive cell death (Levine et al. 1994), was shown to be regulated in part by the PI-PLC activated by an elicitor (Legendre et al. 1993). A glycoprotein elicitor from the phytopathogenic fungus Verticillium albo-atrum, which triggers $\mathrm{Ca}^{2+}$-mediated phytoalexin accumulation, induced a 100 to $160 \%$ increase of $\mathrm{IP}_{3}$ over a water control in lucerne (Medicago sativa) suspension culture cells (Walton et al. 1993). These observations suggest a possible role of $\mathrm{IP}_{3}$ signals in the regulation of host defenses following elicitation. However, whether such a regulation plays any role in the activation of plant defense mechanisms in response to pathogen infection is not known.

We investigated the possible role of $\mathrm{IP}_{3}$ in the expression of plant defenses in the soybean cell suspensions and Pseudomonas syringae pv. glycinea (Psg) interaction. The cell suspensions, prepared from the cultivar Williams 82 , carry a resistance gene Rpg2 that confers resistance against Psg carrying the avirulence gene avrA. However, Williams 82 does not carry the resistance gene (Rpg3) corresponding to avrC and is susceptible to the $P s g$ strain that carries $a v r C$ but not $a v r A$. This cell culture shows a strong oxidative burst following infection with Psg(avrA) but not with Psg(avrC) (Levine et al. 1994). We measured $\mathrm{IP}_{3}$ content in soybean cells following infection with both strains of $P s g$ and have observed that $\mathrm{IP}_{3}$ content decreased after inoculation with either strain of Psg. 
Suspension cell culture of soybean (Glycine max L.) cultivar Williams 82 was maintained at $25^{\circ} \mathrm{C}$ in the dark on an orbital shaker (130 rpm; G10 Gyrotory Shaker; New Brunswick Scientific, Edison, NJ) in Murashige-Skoog (MS) medium (Murashige and Skoog 1962) supplemented with $2.22 \mu \mathrm{M}$ 6benzylaminopurine and $3 \mathrm{mg}$ of picloram and vitamins per liter. Cultures were transferred every 7 days by diluting fivefold in fresh MS medium, and experiments were performed 3 to 5 days after transfer.

Psg race 4 containing either the $a v r A$ or $a v r C$ gene (Keen and Buzzell 1991) was maintained at $28^{\circ} \mathrm{C}$ on King's medium B (KMB; King et al. 1954) plates with $50 \mu \mathrm{g}$ of streptomycin or kanamycin per ml, respectively. Liquid cultures were prepared by inoculating KMB broth containing an appropriate antibiotic with a single colony of plate cultures, and grown for $18 \mathrm{~h}$ at $28^{\circ} \mathrm{C}$ with shaking. The overnight culture was centrifuged, and resuspended in sterile water for inoculation of soybean cell cultures. The final concentration of the bacteria in inoculated suspension cultures was adjusted to optical density (OD) $A_{600}=0.1$.

$\mathrm{H}_{2} \mathrm{O}_{2}$ production by the oxidative burst was measured by the quenching of scopoletin fluorescence at $460 \mathrm{~nm}$ following excitation at $350 \mathrm{~nm}$ (Root et al. 1975). Briefly, $5 \mu \mathrm{l}$ of $2 \mathrm{mM}$ scopoletin was added to cell culture and incubated for $5 \mathrm{~min}$, and fluorescence was determined spectrophotometrically.

To evaluate the defense activity against the pathogen, phenylalanine ammonia-lyase (PAL) activity was assayed by incubating $\left[{ }^{14} \mathrm{C}\right]$ phenylalanine with the crude cell extracts. Cinnamic acid, a product of the PAL enzymatic activity, was extracted with toluene for scintillation counting (Legrand et al. 1976).

We measured $\mathrm{IP}_{3}$ content with a commercially available radioreceptor assay kit (TRK 1000; Amersham International, Little Chalfont, Buckinghamshire, U.K.). Crude extract of soybean cells was prepared according to the method of Legendre et al. (1993). In short, $1 \mathrm{ml}$ of suspension culture samples was collected at appropriate sampling times in microtubes, frozen in liquid nitrogen immediately, and stored at $-80^{\circ} \mathrm{C}$ until use. Extraction was done by adding $500 \mu \mathrm{l}$ of $15 \%$ trichloroacetic acid to each sample and vortexing vigorously. The samples were subsequently centrifuged at $10,000 \times g$ for $20 \mathrm{~min}$ to remove insoluble material and the supernatants were extracted four times with $5 \mathrm{ml}$ of water-saturated ethyl ether. The samples were then neutralized to $\mathrm{pH} 7.5$ by adding an appropriate amount ( 5 to $8 \mu \mathrm{l}$ ) of $16 \% \mathrm{Na}_{2} \mathrm{CO}_{3}$. The radioreceptor assay was performed according to the manufacturer's protocol. The binding protein used in the kit is specific for inositol 1,4,5-trisphosphate, and discriminates against other isoforms of $\mathrm{IP}_{3}$, or other inositol phosphates. Cellular $\mathrm{IP}_{3}$ content was standardized to unit fresh weight.

To confirm the results obtained with the radioreceptor assay, we performed high performance liquid chromatography (HPLC). myo- $\left[{ }^{3} \mathrm{H}\right]$ inositol (NEN Life Science Products; Boston) was added to a 3-day-old cell culture to a final concentration of $50 \mu \mathrm{Ci} / \mathrm{ml}$. The cells were then incubated for 2 days. The cell cultures were grown in inositol-free MS medium for 10 days prior to labeling. A filter-sterilized solution of glucuronic acid $(100 \mu \mathrm{g} / \mathrm{ml}$; Aldrich, Milwaukee, WI) was added to prevent incorporation of myo- $\left[{ }^{3} \mathrm{H}\right]$ inositol to glucuronic acid (Loewus and Loewus 1980). Treatments were made by adding $100 \mu \mathrm{l}$ of $10 \times \mathrm{MS}$ salts solution, MS salts, and Psg $\left(A_{600}=\right.$
1.0 ), or water as a control to an aliquot of suspension cells $(900 \mu \mathrm{l})$. Thirty minutes after the treatment, the samples were harvested in microtubes and immediately frozen in liquid nitrogen. The samples were stored in $-80^{\circ} \mathrm{C}$ until use. A crude extract of soybean cells was prepared in the same manner as for a radioreceptor assay.

The separation of inositol phosphates by HPLC was based on the method of Irvine et al. (1985). The Partisil 10 SAX anion exchange column (Phenomenex, Torrance, CA) was initially washed with water for $8 \mathrm{~min}$, and then the eluant (1.7 $\mathrm{M}$ ammonium formate adjusted to $\mathrm{pH} 3.7$ with phosphoric acid) was increased linearly to $100 \%$ over $24 \mathrm{~min}$, and the buffer held at this concentration for $10 \mathrm{~min}$. After the elution, the buffer concentration was decreased linearly to water over 2 min. Ninety-five fractions were collected over the elution period, and analyzed by scintillation counting. Peaks were identified by comparison with those of authentic standards.

The change in $\mathrm{IP}_{3}$ content can be a result of changes either in the rate synthesis or degradation of $\mathrm{IP}_{3}$. We examined whether there is any difference in phosphatase activities on $\mathrm{IP}_{3}$ between the water control and infected cells. The method was based on the report of Joseph et al. (1989). Two milliliters of suspension cells was inoculated with $P s g(a v r A)$ at final OD $A_{600}=0.1$, or water. Cells were centrifuged at $1,000 \times g$ for 10 min and the pellets were resuspended in buffer A $(120 \mathrm{mM}$ $\mathrm{KCl}, 20 \mathrm{mM}$ Tris/HEPES [ $N$-2-hydroxyethylpiperazine- $N{ }^{\prime}-2$ ethanesulfonic acid], $5 \mathrm{mM}$ EGTA, and $1 \mathrm{mM}$ dithiothreitol, $\mathrm{pH}$ 7.2). Samples were ground with a glass homogenizer in buffer A containing $1 \mu \mathrm{g} / \mathrm{ml}$ each of aprotinin, pepstatin, leupeptin and antipain (Sigma, St. Louis, MO). The crude extract was centrifuged at $755 \times g$ for $5 \mathrm{~min}$, and the supernatant was centrifuged at $60,000 \times g$ for $60 \mathrm{~min}$. The supernatant was desalted on a PD-10 column (Amersham Pharmacia Biotech, Uppsala, Sweden). The column was equilibrated with $35 \mathrm{ml}$ of buffer A, and was loaded with $2.5 \mathrm{ml}$ of the crude extract. The sample was eluted with $3.5 \mathrm{ml}$ of buffer A.

Dephosphorylation was assayed in a buffer consisting of $120 \mathrm{mM} \mathrm{KCl}, 20 \mathrm{mM}$ Tris/HEPES, and $0.3 \mathrm{mM} \mathrm{MgCl}_{2}$ (buffer B). The reaction was carried out at $30^{\circ} \mathrm{C}$ by adding $450 \mu \mathrm{l}$ of crude extract to a $1-\mathrm{ml}$ reaction mixture containing $0.3 \mu \mathrm{Ci}$ of tritium-labeled $\mathrm{IP}_{3}$ and $15 \mu \mathrm{M}$ unlabeled $\mathrm{IP}_{3}$. The reaction was stopped after $15 \mathrm{~min}$ by adding $500 \mu \mathrm{l}$ of $15 \%$ trichloroacetic acid, followed by extraction with $5 \mathrm{ml}$ of watersaturated ethyl ether four times. The samples were neutralized to $\mathrm{pH} 7.0$ by adding appropriate volumes of $16 \% \mathrm{Na}_{2} \mathrm{CO}_{3}$. Phosphatase products were analyzed by HPLC by the same method as for $\mathrm{IP}_{3}$ analysis. Injection volume was $200 \mu \mathrm{l}$.

We examined the change in cellular $\mathrm{IP}_{3}$ content for a 3 -h period following pathogen inoculation. $\mathrm{IP}_{3}$ content in all treatments including the water control started to show a decrease immediately following treatments. However, in Psg(avrA)and Psg(avrC)-inoculated cells, the decrease was much greater than that of the water control treatment (Fig. 1A). In our suspension culture systems, $\mathrm{IP}_{3}$ levels fluctuate for unidentified reasons. The fluctuation appears to be synchronous among all treatments. Thus, if we compare the $\mathrm{IP}_{3}$ levels, in the cells inoculated with the pathogens, with the $\mathrm{IP}_{3}$ levels in the water control as the background, the depressed $\mathrm{IP}_{3}$ content in the former was maintained throughout the experiment.

In most PI-PLC studies, the $\mathrm{IP}_{3}$ peak has been reported to be observed within seconds or minutes following treatment. 
However, we did not observe any significant difference in $\mathrm{IP}_{3}$ content among Psg(avrA)- or Psg(avrC)-infected cells and the water control within 3 min following treatment (Fig. 1B). An oxidative burst, considered to be avrA gene-specific (Levine et al. 1994), was observed in Psg(avrA)-inoculated cells 3 to 4 $\mathrm{h}$ after inoculation (Fig. 1C). PAL enzyme activity, which is commonly associated with plant defense response to pathogens, was gradually increased in both Psg(avrA)- and Psg(avrC)-inoculated cells, with higher activities observed for Psg(avrA)-inoculated cells (Fig. 1D).

Addition of MS salts in cell suspensions caused an increase in the basal cellular $\mathrm{IP}_{3}$ levels to several-fold (Fig. 2). When the cells were treated with both MS salts and Psg(avrA), the $\mathrm{IP}_{3}$ increase was less than that observed for the MS saltstreated cells (Fig. 2).

The decrease in cellular $\mathrm{IP}_{3}$ content in pathogen-infected cells was also demonstrated by HPLC. At $30 \mathrm{~min}$ following infection or treatment with MS salts, the amount of $\mathrm{IP}_{3}$ in the cells treated with both MS salts and Psg(avrA) was significantly smaller, compared with that in cells treated only with MS salts (Fig. 3), confirming the results obtained with the radioreceptor assay.

The decrease in $\mathrm{IP}_{3}$ levels we observed in pathogen-infected cells appears to be contradictory to the increase in $\mathrm{IP}_{3}$ content reported previously in elicitor-treated cells (Legendre et al.

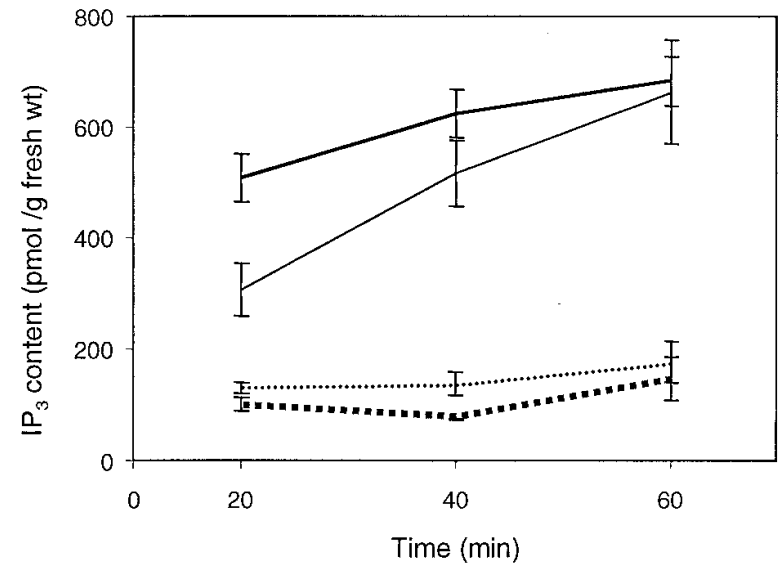

Fig. 2. Effect of Pseudomonas syringae pv. glycinea (Psg) Psg(avrA)inoculation on cellular cytosolic inositol 1,4,5-trisphosphate $\left(\mathrm{IP}_{3}\right)$ content of Murashie-Skoog (MS) salts treated cells. Cellular $\mathrm{IP}_{3}$ content was measured by a commercial radioreceptor assay kit. Data are means of three replications. Bars indicate standard errors of mean. Broken bold line, inoculated with $\operatorname{Psg}(\operatorname{avrA})$; broken regular line, water control; solid bold line, MS-treated cells; solid regular line, cells treated with MS salts and $\operatorname{Psg}(a v r A)$.
A

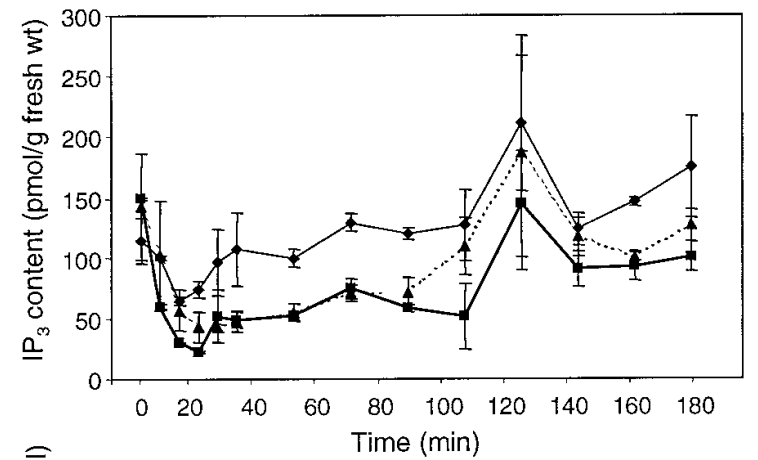

C

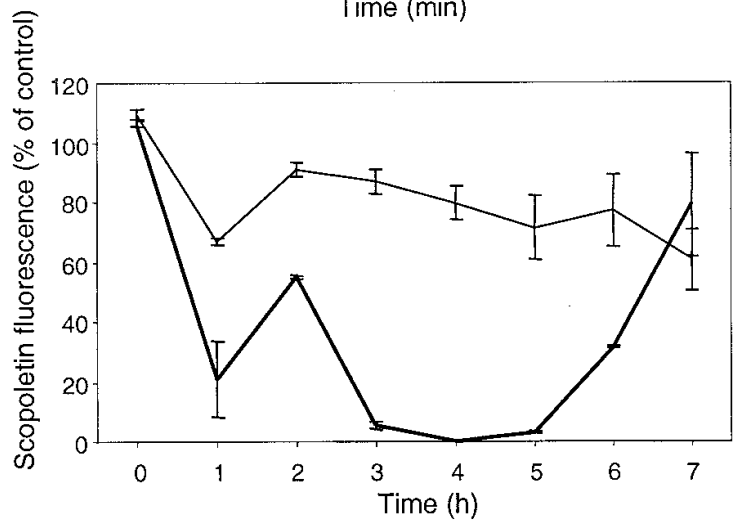

B

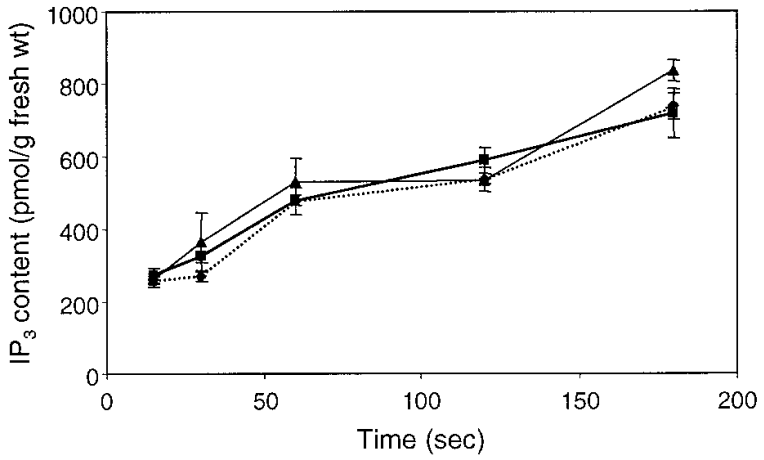

D

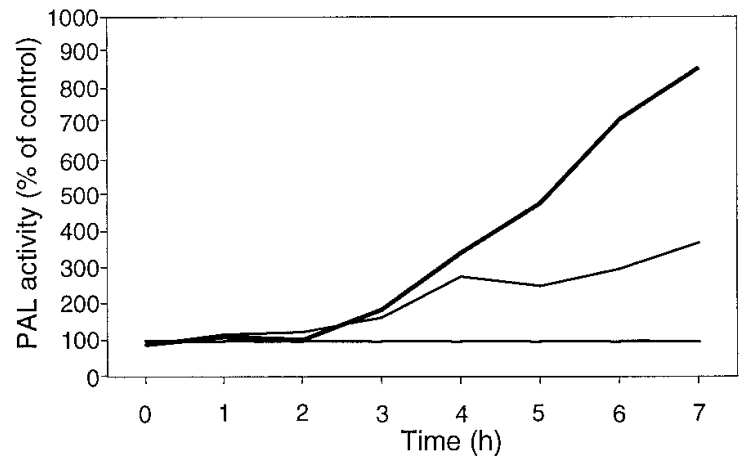

Fig. 1. Changes in cytosolic inositol 1,4,5-trisphosphate $\left(\mathrm{IP}_{3}\right)$ content, $\mathrm{H}_{2} \mathrm{O}_{2}$ generation, and phenylalanine ammonia-lyase (PAL) enzyme activity in cells infected with Pseudomonas syringae pv. glycinea (Psg) Psg(avrA) or Psg(avrC). Regular line, Psg(avrC)-infected cells; bold line, Psg(avrA)infected cells; broken line, water control. A and $\mathbf{C}$, Data are means of two replications. B, Data are means of three replications. Bars indicate standard errors of mean. A, Changes in cellular $\mathrm{IP}_{3}$ content over $3 \mathrm{~h}$. Cellular $\mathrm{IP}_{3}$ content was measured by a commercial radioreceptor assay kit. B, Short-term changes in $\mathrm{IP}_{3}$ content between $15 \mathrm{~s}$ and $3 \mathrm{~min}$ following addition of water or inoculum. Absolute values of $\mathrm{IP}_{3}$ appear to vary among experiments. $\mathbf{C}$, $\mathrm{H}_{2} \mathrm{O}_{2}$ generation measured as quenching of scopoletin fluorescence. Depletion of scopoletin fluorescence in cell culture indicates $\mathrm{H}_{2} \mathrm{O}_{2}$ production by the cells. Data are expressed as percentages of those of the water control values. D, PAL enzyme activity measured by production of ${ }^{14} \mathrm{C}-1$ labeled cinnamic acid after labeling with $\left[{ }^{14} \mathrm{C}\right]$ phenylalanine. Data are percentage of radioactivity over water control. 
1993; Walton et al. 1993). This indicates that the changes in elicitation may not reflect the changes that occur in infected cells. It is conceivable that in a pathogen attack, whether by a virulent or avirulent strain, much of the energy must be utilized in defense, at the expense of the housekeeping cell functions. In parsley (Petroselinum crispum) suspension cells, UV irradiation or fungal elicitor treatment causes transcriptional activation of defense-related genes and a deactivation of cell cycle-related genes (Logemann et al. 1995).

The HPLC profiles of inositol phosphates for the water control and infected cells were similar when radiolabeled $\mathrm{IP}_{3}$ was added to crude extracts to assay phosphatase activities (Fig. 4B,C). However, the amount of undegraded $\mathrm{IP}_{3}$ in $\operatorname{Psg}(\operatorname{avrA})$-infected cells was greater than that in the water control (Fig. 4D), indicating that the rate of $\mathrm{IP}_{3}$ degradation is faster in uninoculated cells. Therefore, the $\mathrm{IP}_{3}$ decrease in Psg(avrA)-infected cells is attributed to reduction in $\mathrm{IP}_{3}$ synthesis. While it is possible that $\mathrm{IP}_{3}$ can be synthesized by pathways other than PI-PLC in other organisms (Drayer et al. 1994; Van Dijken et al. 1996), it was shown that the plant $\mathrm{IP}_{3}$ is an enzymatic product of PI-PLC (Brearley et al. 1997). Thus, deactivation of PI-PLC is most likely responsible for the infection-specific reduction in $\mathrm{IP}_{3}$ content. PI-PLC plays an important role in cell growth in yeast and animals (Flick and Thorner 1993; Yoko-o et al. 1993; Berridge 1993). Growth retardation due to aluminum toxicity was attributed to PI-PLC inhibition in plant (Jones and Kochian 1995). A gravitation-stimulated $\mathrm{IP}_{3}$ increase has been proposed as a signal for pulvinus cell elongation in maize (Perera et al. 1999). PI-PLC also most likely plays a major role in the DNA synthesis in soybean cell suspension following replenishment of cell culture medium (T. Shigaki and M. K. Bhattacharyya, unpublished). In plants, most likely the $\mathrm{IP}_{3}$ signal pathway is constitutive, as shown by the higher resting state $\mathrm{IP}_{3}$ contents (this study and Perera et al. 1999), and probably plays a major role in cell division, growth, and elongation. In infected cells, such functions are most likely inhibited through the reduction of $\mathrm{IP}_{3}$ content. This enables the utilization of host energy supply in meeting the new demands of a host-pathogen interaction. We speculate that the signal(s) of either plant or pathogen origin suppresses the PI-PLC following infection so that plant metabolites are utilized (i) in the synthesis of defense-

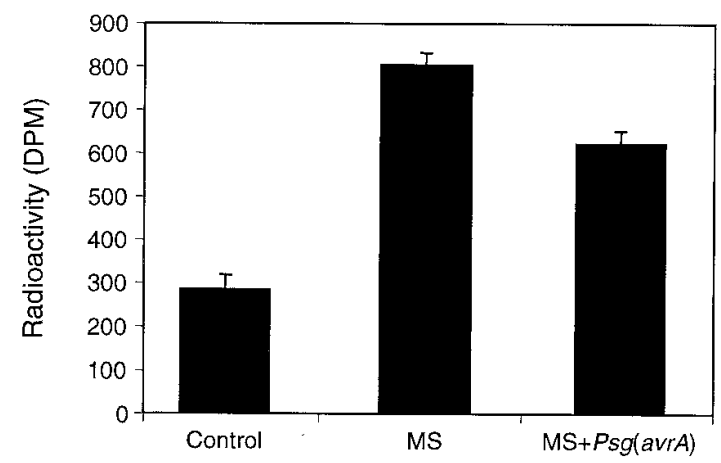

Fig. 3. Reduction of cellular cytosolic inositol 1,4,5-trisphosphate $\left(\mathrm{IP}_{3}\right)$ content in Pseudomonas syringae pv. glycinea (Psg) Psg(avrA)-infected cells measured by high performance liquid chromatography (HPLC). Samples were collected 30 min after treatment. Radioactivity of the peak corresponding to inositol 1,4,5-trisphosphate was measured. Data are means of three replications. Bars indicate standard errors of the mean.
A

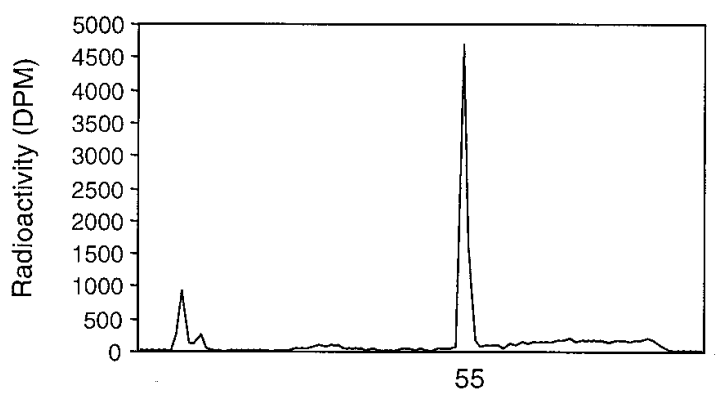

B

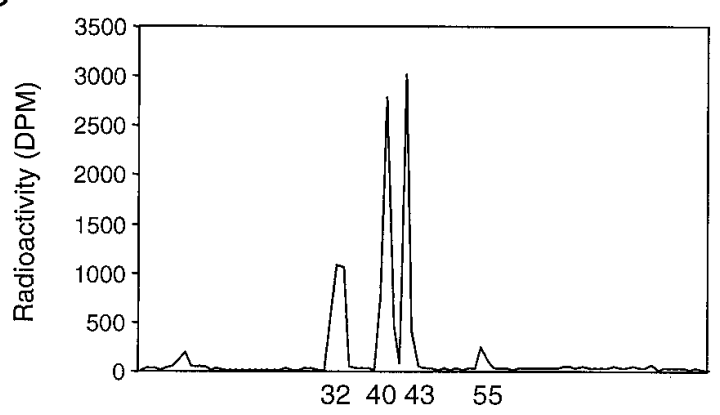

C

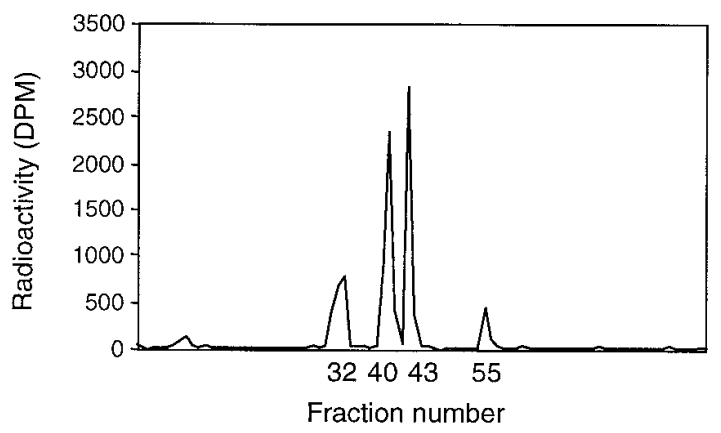

D

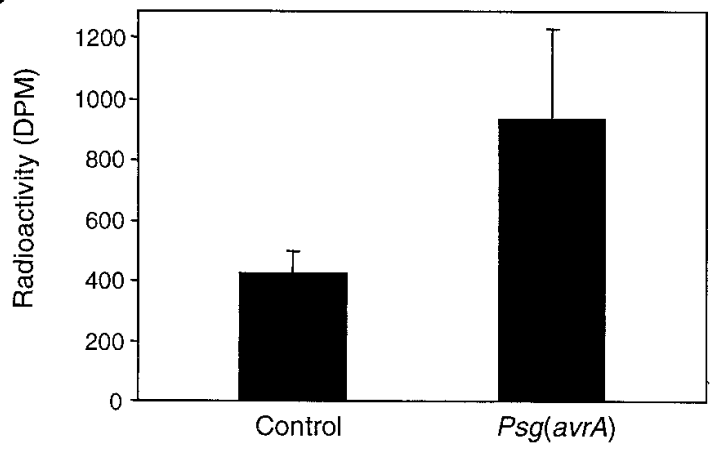

Fig. 4. High performance liquid chromatography (HPLC) profiles of inositol phosphates following incubation of $\left[{ }^{3} \mathrm{H}\right]$ cytosolic inositol 1,4,5trisphosphate $\left(\mathrm{IP}_{3}\right)$ in crude extracts from Pseudomonas syringae pv. glycinea (Psg) Psg(avrA)-infected cells or water control. Fractions number 55 and 40 correspond to $\mathrm{IP}_{3}$ and $\mathrm{I}(1,4) \mathrm{P}_{2}$, respectively. Fraction number 32 and 43 are most likely various isoforms of inositol monophosphates and $\mathrm{I}(4,5) \mathrm{P}_{2}$, respectively. A, Boiled crude extract as a negative control. B, Extract from water control. C, Extract from Psg(avrA)infected cells. D, Amount of undegraded $\mathrm{IP}_{3}$. Data represent means of three replications. Bars indicate standard error of the mean. 
related compounds at the expense of housekeeping functions such as cell division and/or (ii) in supplementing the growth of plant pathogens.

\section{ACKNOWLEDGMENTS}

We thank Jack W. Blount for assistance in HPLC analysis, and Richard A. Dixon, Robert A. Gonzales, and Christian Dammann, for critical reading of the manuscript. We extend our thanks to Darla F. Boydston for the preparation of figures. This work was supported by the Samuel Roberts Noble Foundation.

\section{LITERATURE CITED}

Berridge, M. J. 1993. Inositol trisphosphate and calcium signaling. Nature 361:315-325.

Brearley, C. A, Parmar, P. N., and Hanke, D. E. 1997. Metabolic evidence for PtdIns(4,5)P2-directed phospholipase $\mathrm{C}$ in permeabilized plant protoplasts. Biochem. J. 324:123-131.

Coté, G., and Crain, R. C. 1993. Biochemistry of phosphoinositide. Annu. Rev. Plant Physiol. Plant Mol. Biol. 44:333-356.

Dennis, E. A. 1983. Phospholipases. Pages 307-353 in: The Enzymes, Vol. 16. Academic Press, New York.

Drayer, A. L., Van der Kaay, J., Mayr, G. W., and Van Haastert, J. M. 1994. Role of phospholipase C in Dictyostelium: formation of inositol 1,4,5-trisphosphate and normal development in cells lacking phospholipase C activity. EMBO J. 7:1601-1609.

Ettlinger, C., and Lehle, L. 1988. Auxin induces rapid changes in phosphatidylinositol metabolites. Nature 331:176-178.

Flick, J. S., and Thorner, J. 1993. Genetic and biochemical characterization of a phosphatidylinositol-specific phospholipase C in Saccharomyces cerevisiae. Mol. Cell. Biol. 13:5861-5876.

Franklin-Tong, V. E., Drøbak, B. K., Allan, A. C., Watkins, P. A. C., and Trewavas, A. J. 1996. Growth of pollen tubes of Papaver rhoeas is regulated by a slow-moving calcium wave propagated by inositol 1,4,5-trisphosphate. Plant Cell 8:1305-1321.

Hartweck, L. M., Llewllyn, D. J., and Dennis, E. S. 1997. The Arabidopsis thaliana genome has multiple divergent forms of phosphoinositol-specific phospholipase C. Gene 202:151-156.

Hirayama, T., Ohto, C., Mizoguchi, T., and Shinozaki, K. 1995. A gene encoding a phosphatidylinositol-specific phospholipase $\mathrm{C}$ induced by dehydration and salt stress in Arabidopsis thaliana. Proc. Natl. Acad. Sci. USA 92:3903-3907.

Irvine, R. F., Änggård, E. E., Letcher, A. J., and Downes, C. P. 1985. Metabolism of inositol 1,4,5-trisphosphate in rat parotid glands. Biochem. J. 229:505-511.

Jones, D. L., and Kochian, L. V. 1995. Aluminum inhibition of the inositol 1,4,5-trisphosphate signal transduction pathway in wheat roots: A role in aluminum toxicity? Plant Cell 7:1913-1922.

Joseph, S. K., Esch, T., and Bonner, W. D. 1989. Hydrolysis of inositol phosphates by plant cell extracts. Biochem. J. 264:851-856.

Keen, N. T., and Buzzell, R. I. 1991. New disease resistance genes in soybean against Pseudomonas syringae pv. glycinea: Evidence that one of them interacts with a bacterial elicitor. Theor. Appl. Genet. 81: 133-138.

King, E. O., Ward, M. K., and Raney, D. E. 1954. Two simple media for the demonstration of pyocyanin and fluorescein. J. Lab. Clin. Med. 44:301-307.

Kopka, J., Pical, C., Gray, J. E., and Müller-Röber, B. 1998. Molecular and enzymatic characterization of three phosphoinositide-specific phospholipase $\mathrm{C}$ isoforms from potato. Plant Physiol. 116:239-250.

Lee, Y., Choi, Y. B., Suh, S., Lee, J., Assmann, S. M., Joe, C. O., Kelleher, J. F., and Crain, R. C. 1996. Abscisic acid-induced phosphoinositide turnover in guard cell protoplasts of Vicia faba. Plant Physiol. 110:987-996.

Legendre, L., Yueh, Y. G., Crain, R., Haddock, N., Heinstein, P. F., and Low, P. S. 1993. Phospholipase C activation during elicitation of the oxidative burst in cultured plant cells. J. Biol. Chem. 268:2455924563.

Legrand, M., Fritig, B., and Hirth, L. 1976. Enzymes of the phenylpropanoid pathway and the necrotic reaction of hypersensitive tobacco to tobacco mosaic virus. Phytochemistry 15:1353-1359.

Levine, A., Tenhaken, R., Dixon, R., and Lamb, C. 1994. $\mathrm{H}_{2} \mathrm{O}_{2}$ from the oxidative burst orchestrates the plant hypersensitive disease resistance response. Cell 79:583-593.

Loewus, F. A., and Loewus, M. W. 1980. myo-Inositol: Biosynthesis and metabolism. Pages 43-76 in: The Biochemistry of Plants. Vol. 3. J. Preiss, ed. Academic Press, New York.

Logemann, E., Wu, S., Schröder, J., Schmelzer, E., Somssich, I. E., and Klaus Hahlbrock. 1995. Gene activation by UV light, fungal elicitor or fungal infection in Petroselinum crispum is correlated with repression of cell cycle-related genes. Plant J. 8:865-876.

Majerus, P. W. 1992. Inositol phosphate biochemistry. Annu. Rev. Biochem. 61:225-250.

Morse, M. J., Crain, R. C., Cote, G. G., and Satter, R. L. 1989. Lightstimulated inositol phospholipid turnover in Samanea saman leaf pulvini increased levels of diacylglycerol. Plant Physiol. 89:724-727.

Morse, M. J., Crain, R. C., and Satter, R. L. 1987. Light-stimulated inositol phospholipid turnover in Samanea saman leaf pulvini. Proc. Natl. Acad. Sci. USA 84:7075-7078.

Munnik, T., Irvine, R. F., and Musgrave, A. 1998. Phospholipid signalling in plants. Biochim. Biophys. Acta 1389:222-272.

Murashige, T., and Skoog, F. 1962. A revised medium for rapid growth and bioassays with tobacco tissue cultures. Physiol. Plant. 15:473497.

Perera, I. Y., Heilmann, I., and Boss, W. F. 1999. Transient and sustained increases in inositol 1,4,5-trisphosphate precede the differential growth response in gravistimulated maize pulvini. Proc. Natl. Acad. Sci. USA 96:5838-5843.

Root, R. K., Metcalf, J., Oshino, N., and Chance, B. 1975. $\mathrm{H}_{2} \mathrm{O}_{2}$ release from human granulocytes during phagocytosis: Documentation, quantitation and some regulating factors. J. Clin. Invest. 55:945-955.

Shi, J., Gonzales, R. A., and Bhattacharyya, M. K. 1995. Characterization of a plasma membrane-associated phosphoinositide-specific phospholipase C from soybean. Plant J. 8:381-390.

Singer, W. D., Brown, H. A., and Sternweis, P. C. 1997. Regulation of eukaryotic phosphatidylinositol-specific phospholipase C and phospholipase D. Annu. Rev. Biochem. 66:475-509.

Van Dijken, P. Bergsma, J. C. T., Hiemstra, H. S., De Vries, B., Van der Kaay, J., and Van Haastert, P. J. M. 1996. Dictyostelium discoideum contains three inositol monophosphatase activities with different substrate specificities and sensitive to lithium. Biochem. J. 314:491-495.

Walton, T. J., Cooke, C. J., Newton, R. P., and Smith, C. J. 1993. Evidence that generation of inositol 1,4,5-trisphosphate and hydrolysis of phosphatidylinositol 4,5-bisphosphate are rapid responses following addition of fungal elicitor which induces phytoalexin synthesis in lucerne (Medicago sativa) suspension culture cells. Cell. Signalling 5: 345-356.

Yoko-o, T., Matsui, Y., Yagisawa, H., Nojima, H., Uno, I., and Toh-e, A. 1993. The putative phosphoinositide-specific phospholipase C gene, PLC1, of the yeast Saccharomyces cerevisiae is important for cell growth. Proc. Natl. Acad. Sci. USA 90:1804-1808. 